\title{
Coaches' Evaluations of Match Performance in Academy Soccer Players in Relation to the Adolescent Growth Spurt
}

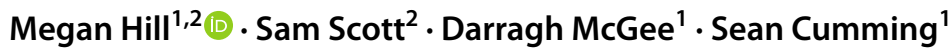

Received: 30 April 2020 / Accepted: 11 July 2020 / Published online: 7 August 2020

(c) The Author(s) 2020

\begin{abstract}
Individual differences in biological maturation present challenges for coaches involved with youth soccer players. Youth in the same chronological age group vary in terms of stage of maturity (pre, circum- and post-pubescent) and rate of growth, but how this affects coaches' evaluations of player performance is unknown. The aim of this study was to compare youth soccer coaches' evaluations of players match performances before, during and post growth spurt in a professional English soccer academy across four seasons. Two hundred and seventy-eight male soccer players in the under-9 to under-16 age-groups had their performances evaluated by their coach on a 4-point Likert scale. For each game, players were categorised by their maturity status estimated using percentage of predicted adult height at the time of observation. A one-way ANCOVA controlling for the level of opposition and game outcome revealed that coaches' evaluations declined from the pre- to during growth spurt stages, however, this was only significant in the under 12 age-group. Further, coaches' evaluations increased again in the post-growth spurt stage, although only significant in the under 15 age-group. Coaches evaluations of player performance appear to vary in accordance with stage of maturity and rate of growth. Practitioners in youth soccer should understand the extent to which maturity status may adversely impact performance and consider this when making talent selection decisions.
\end{abstract}

Keywords Soccer $\cdot$ Maturity $\cdot$ Growth $\cdot$ Adolescence $\cdot$ Evaluation

\section{Introduction}

Traditionally, academy soccer players train and compete in groups dictated by their chronological age (e.g., under 11 years, under 12 years). Children of the same age can, however, demonstrate significant variation in biological maturity with some individuals entering puberty well in advance or delay of their same age peers [28]. Children of the same age have been shown to vary by as much as 5-6 years in terms of skeletal age, an established proxy of maturation in youth [19].

Individual differences in biological maturation present significant challenge for those involved in the identification and development of talented young athletes [10]. Within any single year age group, a coach will have to manage, train and

Megan Hill

m.hill2@bath.ac.uk

1 Department for Health, University of Bath, Bath BA2 7AY, UK

2 Sports Science and Medicine Department, Southampton Football Club, Southampton, UK evaluate players who vary markedly in size, athleticism, and stage of maturity (i.e., pre-, circum-, and post-pubescent) [5, 10]. Although children can demonstrate marked variation in the timing of maturation, the pattern of growth is generally the same for all healthy children [42]. It occurs distal to proximal, so the extremities undergo growth first (feet, hands and head), followed by the arms and legs, the length and then the width of the trunk $[1,25,48]$.

Growth in childhood is steady and predictable, with boys and girls gaining approximately $5-7 \mathrm{~cm}$ and $2-3 \mathrm{~kg}$ per year from early- to late-childhood [25, 40, 45]. In childhood, growth in stature is disproportionally greater in the extremities (i.e. arms and legs) than the torso resulting in physique that has comparatively greater leg length $[8$, 25]. Gains in mass during childhood result from both fat and fat-free mass, with modest increases in lean mass and slight reductions in relative fat mass [25]. Improvements in physical fitness are also modest, with steady, predictable and linear improvements in speed, strength, power and aerobic capacity [3]. Whereas children who mature in advance of their peers tend to be taller and heavier than their same age 
peers, they typically do not demonstrate marked advantages in athleticism [25].

Individual differences in biological maturation have greater consequence at the onset of puberty [27]. The age at which children enter puberty is highly variable and determined by hereditary (i.e., genetic) and environmental/behavioural factors (e.g., stress, physical activity, nutrition) [8]. The hormonal changes mark the onset of puberty, occur on average, around 9-10 years of age in males. The more overt and physical changes associated with puberty (i.e., changes in secondary sex characteristics, growth spurt) do not, however, emerge until approximately 11-12 years of age [25]. The pubertal growth spurt is the most salient feature of puberty and characterised by rapid increases in stature then, approximately 3-6 months later, mass [25, 40]. Peak height velocity (PHV), the most rapid point of growth in stature, occurs at approximately 14 years of age in boys yet varies relative to timing $[3,25,30]$. Whereas early maturing boys may achieve PHV at 11 or 12 years of age, late maturing boys may not experience PHV until 16 or 17 years of age. Means values for growth in stature at PHV generally fall between 8 and $14 \mathrm{~cm}$ per year [25], though tend to be greater in early maturing males. Due to the saltatory (i.e., episodic) nature of growth in, it is not uncommon to record notably higher growth rates, especially if a child is assessed on a more frequent basis [3, 29]. During puberty, growth is predominantly in the upper torso. Peak gains in mass (peak weight velocity, PWV) typically occur 3-6 months following PHV and are largely attributable to gain in lean mass. Rates of growth in mass during puberty approximate 10-12 kg per year, though vary across individuals [40]. As with stature, early maturing boys experience greater pubertal gains in lean mass than their late maturing peers [31]. After PHV and $\mathrm{PWV}$, growth velocity in stature decreases, ceasing when adult (i.e., mature) stature is attained [8]. By the end of the growth spurt all body parts return to proportion.

Aligned with the adolescent growth spurt is the peak development of many physiological and functional attributes $[35,36]$. Longitudinal research has shown improvement in various tests of functional capacity vary relative to the timing of the adolescent growth spurt [3]. The rate of improvement of limb speed occurs 18-24 months before PHV, flexibility increases 6 months before PHV and strength and power increases 6-12 months after PHV [4, 44]. The development of these attributes is associated with PHV, however with the variability in the timing and tempo of growth and maturation, means there is a consequential variability in the development of physical and physiological characteristics within a group [26]. As a result, the comparison players test scores according to chronological age if greatly confounded by differences in pubertal timing. Importantly, elite level football requires highly developed physical characteristics such as speed, power and agility $[43,50]$. Thus, growth and maturity should be considered when evaluating players and making talent identification decisions [10].

The physical and athletic benefits associated with puberty in males are well documented [5, 10, 25, 32]. What is less clear, however, is the extent to which these changes may also adversely impact athletic performance. Adolescent awkwardness is a concept that has been proposed and widely debated within the field of paediatric exercise. The phenomenon, first described by Homburger in [3], refers to a temporary disruption in neuromuscular control and proprioceptive ability that coincides with the adolescent growth spurt [3,23]. Research by Hirtz and Starosta found $90 \%$ of boys showed clear, often considerable, impairment of coordination aligned with their growth spurt [16]. Awkwardness has been attributed to a combination of factors including rapid and asynchronous change in body size, composition and physique, reductions in mobility, flexibility and coordination, marked changes in strength and power, and developmental changes in how the brain assimilates and processes information about body positioning [18, 38, 47]. Anecdotally, growing teenagers are often described as clumsy and awkward in their movements. There is, however, limited empirical evidence to support this concept or an associated decline in athletic performance [11, 26]. This lack of evidence may, however, be due to the complex and transient nature associated with both identifying and measuring the phenomena [18] and a lack of longitudinal research investigating changes in performance during adolescence. That said, emerging evidence suggests at least a plateau or decline in tasks requiring balance and coordination during the growth spurt, especially in boys [3, 38, 41]. Speed ( $30 \mathrm{~m}$ sprint time) has also been shown to be impaired in the year preceding PHV, potentially due to the growth spurt commencing in the lower limbs [36]. That said, despite a strong body of evidence, the concept of "adolescent awkwardness" is generally accepted within the coaching community, especially in sports and activities that require fine motor control and/or enhanced mobility and flexibility [3].

Another concern pertaining to the pubertal growth spurt is that children are more vulnerable to certain types of injury during this stage of development $[6,15,38,46]$. Risk factors that are unique to this adolescent phase include vulnerability of growth plates, differences in biological and chronological age, and an asynchrony between bone lengthening and mineralisation [6]. PWV, the maximum rate of increase in body mass, occurs shortly after PHV [40], where muscle mass increases rapidly with a consequential increase in forces the athlete can produce. Adolescent awkwardness, or a decline in motor coordination, and an increase in forces produced means athletes may also increase susceptibility to injury during puberty [46, 49]. Growth related disorders such as Osgood Schlatter and Sever's disease cause pain in the knee and the heel respectively and are often seen in youth playing sports who are during and beginning their growth spurt 
respectively [37]. Thus, players experiencing peak height velocity are particularly vulnerable to pain and traumatic injuries [46].

The adolescent growth spurt and the accompanying changes may adversely impact playing performance academy soccer. Players undergoing their adolescent growth spurt experience several changes and affects in which players pre or post growth will not be facing to the same extreme. Youth in their growth spurt will be experiencing advancements in their physical capabilities but may also be experiencing awkwardness and pain or injury associated with their increased growth. Research has shown performances in physical testing scores to be affected by this adolescent growth spurt [36]. Although physical testing scores are a valuable tool for talent identification, a coach's subjective opinion of players' match performances is pivotal in whether young players are retained or released $[12,24,50]$. It is, therefore, important to understand if this adolescent phase of accelerated growth influences coaches' evaluations of game performance.

In light of the previous discussion, the purpose of this investigation is to consider the impact of the adolescent growth spurt upon coach evaluations of player performance in academy soccer. Consistent with the concept of adolescent awkwardness, it is hypothesised that coaches' evaluations of player "match performances" will vary relative to their stage of development. More specifically, it is expected that players will receive poorer match grades during the growth spurt than pre- and post-growth spurt.

\section{Method}

\section{Participants}

The sample for this study was made up of under-9 to under16 age group players registered for a category one Premier League Football Academy between July 2014 and June 2018. Data was collected from all academy games within this period (tournaments and games where a player played less than $40 \mathrm{~min}$ game time were excluded). Within this period, 278 participants were included, however many players participated in multiple games over the four seasons and therefore multiple data points per player were collected.

Through the process of registering with the Premier League Football academy, individual players and their parents/guardians provide written informed consent to the routine collection of data and the potential use of this data for research purposes. All measurements of height and weight were taken on a voluntary basis and participants had the right to not be assessed. The Research Ethics Approval Committee for Health of Bath University (REACH) approved this research study and the right to use the retrospective data.

\section{Biological Maturity}

Percentage of predicted mature adult height attained at the time of observation was the estimate of biological maturity status used [39]. Within a chronological age group, players with a higher estimated percentage of predicted adult height are assumed to be more mature than players with a percentage more removed from their predicted adult height. The Khamis-Roche method was used to predict adult height, utilising current age, height and weight of the player and the biological parents' mean height [20]. The median error bound for the Khamis-Roche method between actual height and predicted height is $2.2 \mathrm{~cm}$ for males aged $4-17.5$ years [20]. Height and weight of the players was measured every 12 weeks by trained academy sports scientists following standardised procedures. Self-reported parents' height was adjusted for overestimation; parents tend to overestimate their height when self-reporting and so the corrective equations by Epstein et al. were applied [Father's adjusted heig $\mathrm{ht}=7.12+(0.953 \times$ reported height in $\mathrm{cm})]$ and [Mother's adjusted height $=5.88+(0.955 \times$ reported height in $\mathrm{cm})]$ $[13,14]$.

For each game, the nearest estimate of biological maturity status was utilised (to be included, this measure had to be within 6 months of the game). The players percentage of predicted adult height attained at the time of observation was then expressed as pre-pubertal, pubertal (during the growth spurt) and late pubertal (post-growth spurt) for each game. Percentages of predicted adult height between $86 \%$ and $95 \%$ were classified as "circa" or during the growth spurt $[2,10$, 42]. Percentages lower than $86 \%$ and greater than $95 \%$ were recorded as pre- and post-growth spurt respectively.

\section{Match Grade, Result and Opposition}

As part of normal procedures within the football academy, all players have every performance assessed and graded by their age-group coach on a scale of one to four. Criteria for grades are outlined by the academy as per what is expected per age group; coaches grade each player from 1 to 4, depending on whether they performed below academy standard, approaching academy standard, meeting academy standard and exceeding academy standard respectively. Accordingly, for every game a player participates, they have a corresponding match grade of one to four indicating their coaches perception of performance (for the match grade to be included in the analysis a player must have played for $40 \mathrm{~min}$ or more to ensure the coach had a good representation of their performance).

Equally, opposition and result of each game across the seasons were recorded. Opposition teams were coded using Premier League Academy Category Status, with the standard of the opposition rated from 1 to 4 , with 1 being most 
elite and 4 being grassroots. Result of each game was coded as a win, loss or a draw. Previous research has shown result and opposition status to influence coach ratings of player performances.

\section{Statistical Methods}

Data was inputted and analyzed using IBM SPSS (version 23). A Chi square test was used to compare the match grades of players across the biological maturity groups. A one-way ANCOVA was conducted to determine a statistically significant difference between the levels of biological maturity (pre, during or post growth spurt) on match grades while controlling for the opposition status and result of that game; this was conducted for the overall sample and for each individual age-group separately. Effect sizes were calculated and interpreted using Cohen's guidelines and significance was set at $P<0.05$ [9].

\section{Results}

A one-way ANCOVA was conducted to determine statistically significant differences in match performance across the different biological maturity groups. It should be noted the assumption for homogeneity of variance was violated for the under 15 age-group, and thus result should be interpreted with some caution; analysis continued due to large sample sizes and controlling for the covariates (result and opposition) was important to the analysis.

The descriptive statistics show the mean and standard deviations for chronological age, percentage of predicted adult height, and match grade for every age group (Table 1). Mean chronological age and percentage of predicted adult height increased with successive age groups. Mean match grade generally decreased as age groups advanced.

The Chi square result showed a significant association between maturity timing and match grade $\left[\chi^{2}(6)=702.8\right.$, $P<0.001$ ) (Table 2). More specifically, lower match grades were overrepresented in the post growth spurt and during growth spurt groups. For the total sample, the ANCOVA showed a statistically significant effect of growth spurt status on match grade after controlling for the opposition and result of the game $[F(3,10856)=188.85, P=0.000$, partial eta squared $=0.03]$. Subsequent pairwise comparisons indicated that the adjusted mean values for match grade were significantly lower for the during growth spurt group than the pre-growth spurt group and for the postgrowth spurt group than the during growth spurt group.

The ANCOVA showed a statistically significant effect of growth spurt status on match grade after controlling for the opposition and result of that game for the under 12's and under 15's (Table 3). For the under 12's the average mean match grade was significantly higher for the players in the team who were pre-growth spurt $(F(3,1509)=$ 15.53, $P=0.000$ ). Similarly, within the under 13's the average mean match grade was higher for the players pregrowth spurt compared to the players who are playing during their growth spurt; however, this was non-significant $(P=0.087)$. For the under 15's however, the average mean match grade was higher for players post growth spurt, compared to players during their growth spurt $[(F(3,1079)$ $=25.851, P=0.000]$.
Table 1 Table to show descriptive statistics across age groups

Table 2 Table to show frequency of match grade classifications by biological maturity status

\begin{tabular}{|c|c|c|c|c|c|c|c|c|}
\hline \multirow[t]{2}{*}{ Age group } & \multirow[t]{2}{*}{$N$} & \multicolumn{2}{|c|}{ Chronological age } & \multicolumn{2}{|c|}{ Match grade } & \multirow[t]{2}{*}{$N$} & \multicolumn{2}{|c|}{$\%$ of $\mathrm{PAH}$} \\
\hline & & M & SD & M & SD & & M & SD \\
\hline Under 9 & 1684 & 8.99 & 0.39 & 2.49 & 0.63 & 1642 & 74.73 & 1.89 \\
\hline Under 10 & 1608 & 9.91 & 0.45 & 2.50 & 0.63 & 1566 & 77.35 & 1.90 \\
\hline Under 11 & 1609 & 10.90 & 0.47 & 2.48 & 0.63 & 1577 & 80.31 & 1.83 \\
\hline Under 12 & 1658 & 11.86 & 0.48 & 2.49 & 0.62 & 1658 & 83.00 & 2.04 \\
\hline Under 13 & 1836 & 12.89 & 0.49 & 2.29 & 0.71 & 1828 & 86.87 & 2.52 \\
\hline Under 14 & 1580 & 13.92 & 0.54 & 2.25 & 0.68 & 1552 & 91.28 & 2.81 \\
\hline Under 15 & 1213 & 14.80 & 0.50 & 2.21 & 0.71 & 1182 & 95.15 & 2.03 \\
\hline Under 16 & 1084 & 15.72 & 0.55 & 1.93 & 0.71 & 1052 & 97.64 & 1.39 \\
\hline
\end{tabular}

\begin{tabular}{lllll}
\hline Maturity status & \multicolumn{4}{l}{ Match grade (expected frequency) } \\
\cline { 2 - 5 } & $1(10.29 \%)(\%)$ & $2(45.45 \%)(\%)$ & $3(42.67 \%)(\%)$ & $4(1.59 \%)(\%)$ \\
\hline Pre-growth (<86\%) & 5.41 & 41.88 & 50.73 & 1.97 \\
During growth (86\%-95\%) & 13.65 & 50.30 & 35.00 & 1.04 \\
Post-growth (>95\%) & 23.03 & 47.76 & 27.79 & 1.42 \\
\hline
\end{tabular}


Table 3 ANCOVA for mean match grade by maturity status for U9-U16 age groups showing adjusted mean match grades

\begin{tabular}{lccrrrr}
\hline \multicolumn{7}{l}{ Mean match grade } \\
\hline Age group & Pre-growth $(n)$ & During $(86-95 \%)(n)$ & Post-growth $(n)$ & $F$ & $P$ & $\eta_{p}^{2}$ \\
\hline Under 9 & $(1503) 2.50$ & & & & & \\
Under 10 & $(1356) 2.51$ & & & 0.33 & 0.564 & 0.000 \\
Under 11 & $(1377) 2.48$ & $(13) 2.58$ & & 15.53 & $\mathbf{0 . 0 0 0}$ & 0.010 \\
Under 12 & $(1220) 2.52$ & $(293) 2.37$ & & 2.94 & 0.087 & 0.002 \\
Under 13 & $(348) 2.36$ & $(1260) 2.29$ & (20) 2.25 & 0.00 & 0.996 & 0.000 \\
Under 14 & $(32) 2.24$ & $(1412) 2.24$ & $(409) 2.36$ & 25.85 & $\mathbf{0 . 0 0 0}$ & 0.023 \\
Under 15 & & $(674) 2.15$ & $(851) 1.93$ & 1.87 & 0.172 & 0.002 \\
Under 16 & & $(93) 1.83$ & & & &
\end{tabular}

Bold Significant at $<0.05$

\section{Discussion}

The purpose of this investigation was to compare youth soccer coaches' evaluations of players' match performance before, during and after the growth spurt. Controlling for opposition status and match outcome, coaches' evaluations of match performance appeared to decline from the pre- to mid-growth spurt phases, before increasing again postgrowth spurt. Although there was a general trend towards a reduction in match performance through the mid-growth spurt stage, it should be noted that the maturity associated differences in coaches' evaluations of match performance only achieved statistical significance in the under 12 and under 15 years age-groups (Fig. 1). Equally, it is important to note that the effect sizes associated with these differences were generally small. That said, these differences may have been attenuated due to the limited range of the scale for assessing match performance (i.e., four point scale) and limited variation in the responses of the coaches. That is, the majority of match grades awarded were either and twos and threes, with markedly less scores of one or four being given. While the differences in under 13's and 16's age groups follow the trend, of superior performance pre- and post-growth spurt, they did not achieve statistical significance. In contrast, the coaches' evaluations of match performance did not vary relative to maturation status in the U14's age group. This may, however, reflect the fact that the majority of all players in this age group were categorised as mid-growth spurt.

The observation that coaches' evaluations of player match performance declined on entry to the growth spurt and then increased post-growth spurt is line with the concept of "adolescent awkwardness". That is, that the rapid changes in size, form and function that accompany the pubertal growth spurt may adversely impact athletic performance during this phase of development [3]. As previously noted, the concept of adolescent awkwardness is generally accepted within the coaching community, despite a lack of empirical evidence [22, 36, 41]. Researchers suggest specific aspects of motor control may be affected during the rapid adolescent growth spurt, such as neuromuscular control, postural stability, and interlimb/intersegmental coordination [18, 38]. Furthermore, regressions in neuromuscular control, postural stability and interlimb coordination will influence important attributes required in football such as speed, agility
Fig. 1 Graph to show mean match grades across the different maturity statuses within each age group (age-groups only included if more than 20 classified in each maturity group)

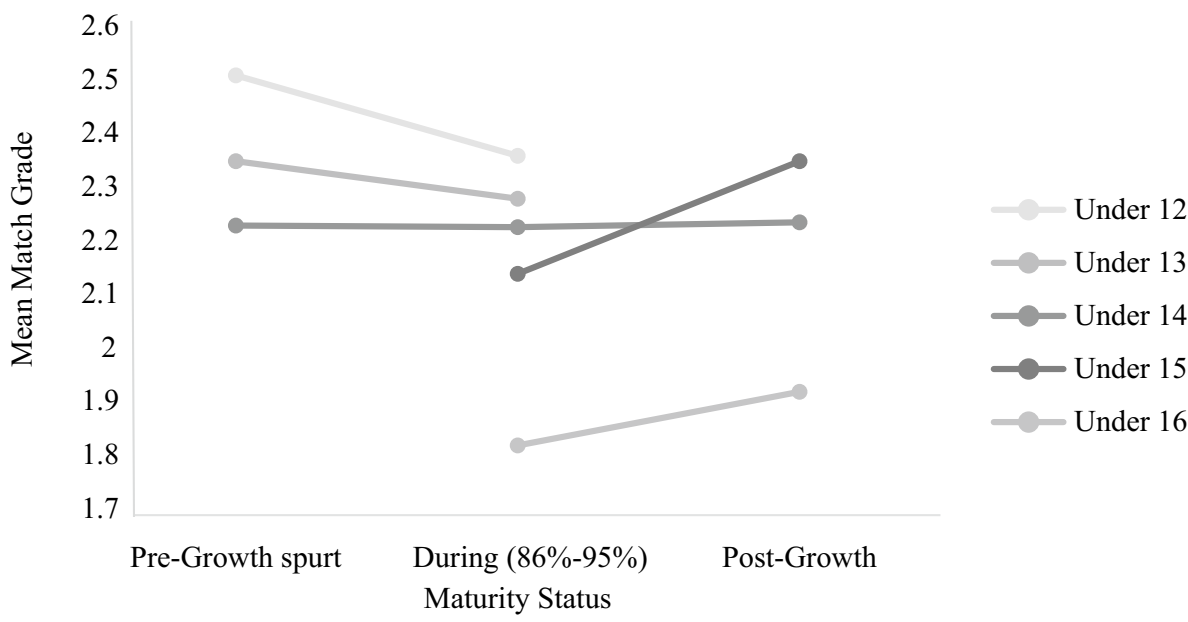


and balance [18]. Adolescents situated in mid-puberty and experiencing their adolescent growth spurt may therefore have disturbances to their motor patterns influencing their ability to perform in matches. Hirtz and Starosta suggest the impairment of rhythm, kinetic differentiation and coordination may appear immediately aligned with the growth spurt or with a 1-year delay [16]. This 1-year delay in coordination may also explain the lower match grades in the post-growth spurt group (Table 2). Equally, expectations of athletes postgrowth spurt may be higher and could explain the perceived lower performance grades. Players pre-growth spurt have not been exposed to these challenges yet; players post-growth spurt have overcome these growth-related challenges and got their growing out of the way [33].

Although it has been argued the "coaches eye" would struggle to pick up on such small regressions in motor control [38], the results of the current investigation suggest maturity associated decrements in performance related to the growth spurt are reflected in coaches' evaluations of match performance. The extent to which coaches are aware how the growth spurt adversely impacts player performance is, however, unclear and worthy of further consideration. As match performance grades are routinely used to inform decision in player selection and retention meetings, it is important that those involved in the decision processes recognise the extent to which maturational status may adversely impact player performance. A player who is not performing well or has experienced a sudden dip in performance may be struggling with the challenges associated with adapting to the changes associated with the growth spurt. It is equally important that the coaches consider how growth-related declines in performance may impact players from a psychological perspective. The need to feel and demonstrate competence is a primary driver of intrinsic and adaptive motivation. A failure to meet these needs may result in frustration, maladaptive coping behaviours, and amotivated behaviour [34]. Accordingly, coaches and practitioners should seek to educate players on the impact of growth upon performance, adapt training programmes accordingly, and help them adjust their expectations during this stage of development, supporting them through the adjustment process.

Anecdotal evidence illustrates the challenges associated with evaluating player ability and future potential during the growth spurt. As an academy player, Gareth Bale experienced a dip in performance through the adolescent growth spurt [17]. As a late developer, this dip in performance coincided with a period where most of his contemporaries had already passed through this phase. As such, his performance relative to his peers were notably poorer. At this timepoint, questions were raised about with regards to whether or not he should be retained or released due to his stagnating progress. Recognising that Gareth was currently in the middle of his growth spurt and the potential challenges this may present, Academy talent selectors decided to retain him; though the decision was only secured by a single vote [7]. With careful adaptation of his training programme and continued support Gareth was able to successfully transition through this phase and go on to become one of the United Kingdom's most expensive transfers when he eventually joined Real Madrid. Although Gareth Bale was retained within the academy system, it is possible that many talented players experiencing similar challenges may have been deselected from academies as a result of growth-related dips in performance. Accordingly, academy practitioners should consider growth rate and maturity status when evaluating players and making decisions pertaining to electing/realising adolescent players.

The first age group to include players categorised as mid-growth spurt was the under elevens. The majority of the players in this age group were, however, categorised as pre-growth spurt. Although the initial onset of puberty for boys occurs around 9-10 years of age, the pubertal growth spurt in boys is a relatively late occurring event $[25,30]$. Coupled with the observation that the selection bias towards early maturing boys does not emerge until approximately 11-12 years of age, the relatively small number of boys categorised as during growth-spurt in this age group is to be expected. Those boys categorised as mid growth spurt in this age group can, by nature of their age and maturation status, are more likely to be early maturing. As one would expect, the proportion of players categorised as mid and post-growth spurt increases sequentially through the age groups. Of particular interest, the under 14 age group was the only cohort in which players of all maturity categories were represented. This suggests this is the age group in which coaches can expect the greatest variances in growth and maturation. This finding is consistent with the observation that mean age for PHV in boys approximates 13.8-14 years of age, and this value is likely to be skewed in soccer due to a disproportional representation of early maturing boys [25]. Despite the greater range of maturational status observed in this age group, the majority of the boys in the under $14 \mathrm{~s}$ were categorised as being in the mid-growth spurt group, with a smaller number of boys designated to be pre- and post-growth spurt. By the under 16 group, the majority of players were identified as post growth spurt, with a smaller number of players categorised as mid-pubertal. Those players categorised as mid-growth spurt in this age group are more likely to be late maturing for their age [25].

Limitations of the study should be noted. Firstly, results of this study are based on one professional football academy and thus may not generalise to other football academies with different coaching values and understanding of the influence of growth and maturity on young players. Another limitation within the current study is the method used to assess match performance. Match grade is a single 
item evaluation of performance on a small scale (1-4) and to date, lacks evidence to support its validity and reliability. That said, the item does present high ecological validity, in that it is the current method utilised by the coaches in this academy system to evaluate player performance and development. It should also be noted that coaches' typically restricted the majority of their evaluations to scores of 2 and 3, with comparatively few players receiving scores of 1 and 4 (Table 2). While restricted sample variance in the variable of interest limits the sensitivity of the analyses and generalisability of the findings [21], it does, paradoxically, make the observation of a maturity associated dip in performance even more surprising. If more sensitive measures of performance were employed the impact of the growth spurt upon player performance may be even greater. Accordingly, future research should seek to examine the impact of the growth spurt upon performance using a diverse and more sensitive range of the methods and measures, including longitudinal, observational and mixed methods designs. Research to determine the validity and reliability of the match grades system is also warranted. Finally, the method used to detect the growth spurt, is an estimation of when the growth spurt is expected to occur. The percentage bracket of $86 \%-95 \%$ of predicted adult height was used as this has been shown to be in line with when the majority of youth would experience the growth spurt [42]. Finally, it should be noted that the impact of the impact of the growth spurt upon player performance development through the growth spurt is likely to be highly individualised. It is likely that many of the players categorised as mid-growth spurt may not have experienced plateaus or declines in performance. Future research should also utilise growth velocity to further validate the growth spurt.

In line with our findings, a player's stage of maturity status and growth rate can influence coaches' perceptions of their performances in some age groups. Generally, players in mid-puberty, experiencing their adolescent growth spurt were perceived to perform lower than their peers pre-growth spurt. Academy coaches and practitioners should understand the possible detrimental effects of growth and maturity for some players and consider this when making selection and retention decisions. Finally, it is important to recognise that not all individuals will experience growth related decrements in performance during puberty and how each individual adapt to change during this stage of development will vary [16]. Although some research has shown $90 \%$ of boys face trouble with coordination in the growth spurt, some individuals may see no decrements in performance and others may see improvements [16]. Nevertheless, the results of this study suggest that the puberty is a developmental stage in which potential growth-related decrements in performance are more likely to observed.
Acknowledgements The authors would like to thank the participating academy coaches and players for their collaboration.

Code Availability IBM SPSS (Version 23), code use available on request.

\section{Compliance with Ethical Standards}

Conflict of interest Megan Hill is a $\mathrm{PhD}$ student, part-funded by Southampton Football Club. Sam Scott is an employee of Southampton Football Club. Sean Cumming has worked in research and consultancy roles for the Football Association and the Premier League.

Open Access This article is licensed under a Creative Commons Attribution 4.0 International License, which permits use, sharing, adaptation, distribution and reproduction in any medium or format, as long as you give appropriate credit to the original author(s) and the source, provide a link to the Creative Commons licence, and indicate if changes were made. The images or other third party material in this article are included in the article's Creative Commons licence, unless indicated otherwise in a credit line to the material. If material is not included in the article's Creative Commons licence and your intended use is not permitted by statutory regulation or exceeds the permitted use, you will need to obtain permission directly from the copyright holder. To view a copy of this licence, visit http://creativecommons.org/licenses/by/4.0/.

\section{References}

1. Anderson GS, Twist P. Trainability of children. IDEA Fit J. 2005;2(3):57-65.

2. Baxter-Jones ADG. Growth, maturation, and training. In: Caine DJ, Russell KW, Lim L, editors. Handbook of sports, medicine and science: gymnastics. Chichester: Wiley; 2013. p. 17-27.

3. Beunen G, Malina RM. Growth and physical performance relative to the timing of the adolescent spurt. Exerc Sport Sci Rev. 1988;16(1):503-40.

4. Beunen G, Malina RM, Van't Hof MA, Simons J, Ostyn M, Renson R, Van Gerven D. Adolescent growth and motor performance: a longitudinal study of Belgian boys. Champaign: Human Kinetics Publishers; 1988.

5. Buchheit M, Mendez-Villanueva A. Effects of age, maturity and body dimensions on match running performance in highly trained under-15 soccer players. J Sports Sci. 2014;32(13):1271-8.

6. Caine D, Purcell L, Maffulli N. The child and adolescent athlete: a review of three potentially serious injuries. BMC Sports Sci Med Rehabil. 2014;6(22):1-10.

7. Calvin M. No hunger in paradise. London: Penguin; 2017.

8. Cameron N, Bogin B. Human growth and development. 2nd ed. London: Elsevier; 2012.

9. Cohen J. Statistical power analysis for the behavioural sciences. 2nd ed. New York: Routledge; 1988.

10. Cumming SP, Lloyd RS, Oliver JL, Eisennnann JC, Malina RM. Bio-banding in sport: applications to competition, talent identification, and strength and conditioning of youth athletes. Strength Cond J. 2017;39(2):34-47.

11. Davies PL, Rose JD. Motor skills of typically developing adolescents: awkwardness or improvement? Phys Occup Ther Pediat. 2000;20(1):19-42.

12. Day D. Craft coaching and the 'discerning eye' of the coach. Int J Sports Sci Coach. 2011;6(1):179-95.

13. Epstein LH, Valoski AM, Kalarchian MA, McCurley J. Do children lose and maintain weight easier than adults-a comparison 
of child and parent weight changes from 6 months to 10 years. Obes Res. 1995;3(5):411-7.

14. Faigenbaum AD, Lloyd RS, Oliver JL. Essentials of youth fitness. Champaign: Human Kinetics; 2019.

15. Froholdt A, Olsen OE, Bahr R. Low risk of injuries among children playing organized soccer: a prospective cohort study. Am J Sports Med. 2009;37(6):1155-60.

16. Hirtz P, Starosta W. Sensitive and critical periods of motor coordination development and its relation to motor learning. J Hum Kinet. 2002;7:19-28.

17. James S. Meet the Man who discovered Gareth Bale- in a six-aside aged nine [online]. The Guardian. 2014. https://www.thegu ardian.com/football/2014/may/17/man-who-discovered-garet h-bale-champions-league-real-madrid. Accessed 24 Apr 2020.

18. John C, Rahlf AL, Hamacher D, Zech A. Influence of biological maturity on static and dynamic postural control among male youth soccer players. Gait Posture. 2018;68:18-22.

19. Johnson A, Doherty PJ, Freemont A. Investigation of growth, development, and factors associated with injury in elite schoolboy footballers: prospective study. BMJ. 2009;338:b490.

20. Khamis HJ, Roche AF. Predicting adult stature without using skeletal age - the Khamis-Roche method. Pediatrics. 1994;94(4):504-7.

21. Lakes K. Restricted sample variance reduces generalizability. Psychol Assess. 2013;25(2):643-50.

22. Lloyd RS, Read P, Oliver J, Meyers RW, Nimpius S, Jeffreys I. Considerations for the development of agility during childhood and adolescence. Strength Cond J. 2013;35(3):2-11.

23. Lloyd RS, Oliver JL, Faigenbaum AD, Myer GD, De Ste Croix MB. Chronological age vs biological maturation: implications for exercise programming in youth. J Strength Cond Res. 2014;28(5):1454-64.

24. Lund S, Soderstrom T. To see or not to see: talent identification in the Swedish Football Association. Sociol Sport J. 2017;34(3):248-58.

25. Malina RM, Bouchard C, Bar-Or O. Growth, maturation, and physical activity. 2nd ed. Champaign: Human Kinetics; 2004.

26. Malina RM, Cumming SP, Morano PJ, Barron M, Miller SJ. Maturity status of youth football players: a noninvasive estimate. Med Sci Sports Exerc. 2005;37(6):1044-52.

27. Malina RM, Rogol AD, Cumming SP, Coelho e Silva MJ, Figueiredo AJ. Biological maturation of youth athletes: assessment and implications. Br J Sports Med. 2015;49(13):852-9.

28. Malina RM, Cumming SP, Rogol AD, Coelho-e-Silva MJ, Figueiredo AJ, Konarski JM, Koziel SM. Bio-banding in youth sports: background, concept, and application. Sports Med. 2019;49(11):1671-85.

29. Marshall WA. Evaluation of growth rate in height over periods of less than 1 year. Arch Dis Child. 1971;46(248):414-20.

30. Marshall WA, Tanner JM. Variations in the pattern of pubertal changes in boys. Arch Dis Child. 1970;45(239):13-23.

31. McKay C, Cumming SP, Blake T. Youth sport: friend or foe? Best Pract Res Clin Rheumatol. 2019;33(1):141-57.

32. Meylan C, Cronin J, Oliver J, Hughes M. Talent identification in soccer: the role of maturity status on physical, physiological and technical characteristics. Int J Sports Sci Coach. 2010;5(4):571-92.

33. Mitchell SB, Haase AM, Malina RM, Cumming SP. The role of puberty in the making and breaking of young ballet dancers: perspectives of dance teachers. J Adolesc. 2016;47:81-9.
34. Nicholls JG. Achievement motivation: conceptions of ability, subjective experience, task choice and performance. Psychol Rev. 1984;91(3):328-46.

35. Pearson DT, Naughton GA, Torode M. Predictability of physiological testing and the role of maturation in talent identification for adolescent team sports. J Sci Med Sport. 2006;9(4):277-87.

36. Philippaerts RM, Vaeyens R, Janssens M, Van Renterghem B, Matthys D, Craen R, Bourgois J, Vrijens J, Beunen G, Malina RM. The relationship between peak height velocity and physical performance in youth soccer players. J Sports Sci. 2006;24(3):221-30.

37. Price RJ, Hawkins RD, Hulse MA, Hodson A. The Football Association medical research programme: an audit of injuries in academy youth football. Br J Sports Med. 2004;38(4):466-71.

38. Quatman-Yates CC, Quatman CE, Meszaros AJ, Paterno MV, Hewett TE. A systematic review of sensorimotor function during adolescence: a developmental stage of increased motor awkwardness? Br J Sports Med. 2012;46(9):649-55.

39. Roche A, Tyleshevski F, Rogers E. Non-invasive measurements of physical maturity in children. Res Q Exerc Sport. 1983;54(4):364-71.

40. Rogol AD, Clark PA, Roemmich JN. Growth and pubertal development in children and adolescents: effects of diet and physical activity. Am J Clin Nutr. 2000;72(2):521S-8S.

41. Ryan D, McCall A, Fitzpatrick G, Hennessy L, Meyer T, McCunn $\mathrm{R}$. The influence of maturity status on movement quality among English Premier League academy soccer players. Sport Perform Sci Rep. 2018;32(1):1.

42. Sanders JO, Qiu X, Lu X, Duren DL, Liu RW, Dang D, Menendez ME, Hans SD, Weber DR, Cooperman DR. The uniform pattern of growth and skeletal maturation during the human adolescent growth spurt. Sci Rep. 2017;7:16705.

43. Stolen T, Chamari K, Castagna C, Wisloff U. Physiology of soccer. Sports Med. 2005;35(6):501-36.

44. Stratton G, Oliver JL. The impact of growth and maturation on physical performance. In: Lloyd RS, Oliver JL, editors. Strength and conditioning for young athletes: science and application. London: Routledge; 2014. p. 3-18.

45. Tanner JM. Fetus into man: physical growth from conception to maturity. Cambridge: Harvard University Press; 1989.

46. van der Sluis A, Elferink-Gemser MT, Coelho-e-Silva MJ, Nijboer JA, Brink MS, Visscher C. Sport injuries aligned to peak height velocity in talented pubertal soccer players. Int J Sports Med. 2014;35(4):351-5.

47. Viel S, Vaugoyeau M, Assaiante C. Adolescence: a transient period of proprioceptive neglect in sensory integration of postural control. Mot Control. 2009;13(1):25-42.

48. Viru A, Loko J, Harro M, Volver A, Laaneots L, Viru M. Critical periods in the development of performance capacity during childhood and adolescence. Eur J Phys Educ. 1999;4(1):75-119.

49. Wik EH, Martínez-Silván D, Farooq A, Cardinale M, Johnson A, Bahr R. Skeletal maturation and growth rates are related to bone and growth plate injuries in adolescent athletics. Scand J Med Sci Sports. 2020;30(5):894-903.

50. Williams A, Reilly T. Talent identification and development in soccer. J Sports Sci. 2000;18(9):657-67. 